\title{
Aortic valve sparing surgery-patient selection and techniques
}

\author{
Vincent Chauvette $^{1}$, Marie-Ève Chamberland ${ }^{2}$, Laurence Lefebvre ${ }^{1}$, Ismail El-Hamamsy ${ }^{3}$ \\ ${ }^{1}$ Department of Cardiac Surgery, ${ }^{2}$ Department of Anesthesiology, Montreal Heart Institute, Universite de Montréal, Montréal, Canada; ${ }^{3}$ Department \\ of Cardiovascular Surgery, Mount Sinai Hospital, Icahn School of Medicine at Mount Sinai, New York NY, USA \\ Contributions: (I) Conception and design: V Chauvette; (II) Administrative support: I El-Hamamsy; (III) Provision of study materials or patients: \\ None; (IV) Collection and assembly of data: V Chauvette, I El-Hamamsy; (V) Data analysis and interpretation: V Chauvette, MÈ Chamberland, L \\ Lefebvre, I El-Hamamsy; (VI) Manuscript writing: All authors; (VII) Final approval of manuscript: All authors. \\ Correspondence to: Ismail El-Hamamsy, MD, PhD. Department of Cardiovascular Surgery, Mount Sinai Hospital, Icahn School of Medicine at Mount \\ Sinai, 1190, 5th Avenue, New York, NY 10029, USA. Email: i.elhamamsy@icm-mhi.org.
}

\begin{abstract}
Aortic valve sparing root replacement (VSRR) is an attractive alternative to composite graft replacement in young patients with root aneurysms. The preservation of a native aortic valve provides more physiologic hemodynamics, avoids the complications associated with valve replacement and is associated with excellent long-term survival. However, this has to be weighed against the risk of reintervention due to valve failure in specific patients. Over the years, studies have shed light on various factors impacting VSRR durability. Specifically, patients' characteristics, anatomical considerations and associated cardiac pathologies all have to be carefully analyzed. Furthermore, several technical aspects are crucial to ensure good long-term outcomes. Issues such as the presence of a bicuspid aortic valve, patients presenting with aortic disease and root aneurysms caused by heritable aortic disorders have been the subject of several studies. The outcomes and conclusions of these research contributions are reviewed and discussed. While the main discussion about VSRR technique used to be around the question of remodeling versus reimplantation, several recent studies have demonstrated that both techniques offer excellent outcomes. More importantly, the focus has shifted towards key technical aspects that may be achieved with both techniques: stabilization of the aortic annulus, creation of neo-sinuses of Valsalva, reduction and stabilization of the sino-tubular junction (STJ) and restoration of cusp geometry within the new aortic root. The aim of this article is to review these important clinical and technical considerations for planning VSRR.
\end{abstract}

Keywords: Aortic valve; valve sparing; patient selection; remodeling; reimplantation

Received: 14 October 2019; Accepted: 24 January 2020; Published: 20 January 2021.

doi: 10.21037 /jovs.2020.02.05

View this article at: http://dx.doi.org/10.21037/jovs.2020.02.05

\section{Introduction}

The modified Bentall procedure (composite valve graft) remains the gold standard surgical approach for patients with aortic root aneurysms. However, composite valve grafts $(\mathrm{CVG})$ are associated with the risks of lifelong anticoagulation or thromboembolism imposed by mechanical valves and those of structural valve deterioration and reoperation associated with bioprostheses $(1,2)$. VSRR techniques, which most commonly refer to remodeling and reimplantation, were introduced by Magdi Yacoub and Tirone David respectively, as alternatives to CVGs $(3,4)$.
Over the years, these techniques have undergone iterative improvements and demonstrated significant benefits in terms of clinically relevant outcomes such as survival, valverelated complications and quality of life when compared with CVGs (5-11).

Nevertheless, the use of VSRR remains limited in most centers (12), which is in part due to the higher degree of technical difficulty of these procedures, and to the risk of reintervention due to aortic regurgitation (AR). Developing expertise with VSRR - as is the case with any reconstructive procedures-is a balance between being highly selective to ensure good long-term outcomes at the expense of surgical 
Table 1 Comparison of characteristics favoring VSRR or CVG

\begin{tabular}{lcc}
\hline Characteristics & Favors VSRR & Favors CVG \\
\hline Young age & $\sqrt{ }$ & \\
No preoperative Al & $\sqrt{ }$ & \\
Poor ventricular function & & $\sqrt{ }$ \\
Bicuspid valve & $\sqrt{ }$ \\
Multiple concomitant interventions & & $\sqrt{ }$ \\
Cusp calcifications, large & & $\sqrt{ }$ \\
fenestrations, cusp retraction & & $\sqrt{ }$ \\
Emergency procedure & & \\
Heritable aortic disorders & $\sqrt{ }$ \\
Patient contemplating pregnancy & $\sqrt{ }$ \\
Lifestyle considerations & $\sqrt{ }$ & \\
\hline
\end{tabular}

VSRR, valve sparing root replacement; CVG, composite valve grafts.

volumes, versus wider inclusion criteria which result in larger surgical volumes, but may be accompanied by less optimal long-term outcomes. Unlike prosthetic valve replacement where reintervention is due to "structural valve degeneration", in reconstructive root surgery, this is due to repair "failure". In an era of increased scrutiny of surgical outcomes, this poses a significant limitation to wider adoption of these techniques. Furthermore, as shown in the Society for Thoracic Surgeons (STS) Database, there is a concerning lack of concentration of aortic root procedures in North America ( $>95 \%$ of centers perform less that 16 aortic root procedures per year), making it difficult to build significant expertise (12).

While these challenges are inherent to any complex surgical procedures, there is little doubt that, in the last decade, significant strides have been made in improving outcomes after VSRR. This owes to several factors such as better multi-modality imaging techniques, standardization of surgical techniques, increased understanding of the technical success factors for aortic valve repair and VSRR and growing knowledge about patient-specific outcomes leading to more careful patient selection. In this article, we aim to discuss important features of patient selection and techniques relevant to VSRR.

\section{Patient selection}

Three main elements should be considered to determine the suitability for a VSRR: (I) patient characteristics (age, elective versus urgent surgery, comorbidities, etc.), (II) feasibility of valve preservation (valve morphology, cusp characteristics) and (III) expected durability. While the first two criteria can be rather objective, the latter is partially a matter of surgical judgement which is inherently subjective. Nevertheless, recent long-term studies of VSRR cohorts are key to inform some of these decisions. Typically, nonelderly patients ( $<65$ years old) with aortic root aneurysms (usually associated with annulo-aortic ectasia) and pliable cusps are considered good candidates for a VSRR. In addition to a thorough patient history, detailed imaging of the aortic valve and root are fundamental for adequate planning of a VSRR procedure. The followings are some important considerations with regarding to patient selection and Table 1 provides a summary of the characteristics favoring VSRR as opposed to CVGs.

\section{Anatomical considerations}

A detailed analysis of the different component parts of the aortic root is primordial: aortic annulus, sinuses of Valsalva, sino-tubular junction (STJ) and aortic valve cusps. The presence or absence of aortic insufficiency (AI) is equally important. In the absence of AI, a VSRR procedure should be the approach of choice and all efforts should be made to preserve the aortic valve. Alternatively, a central jet of AI suggests dilatation of the aortic annulus or STJ, whereas an eccentric jet is indicative of concomitant aortic cusp prolapse or retraction. Important considerations on preoperative imaging and intraoperative direct examination are the absolute diameters of the various levels of the aortic root. Particular consideration should be given to aortic annular dimensions. Excessive dilatation of the aortic annulus $(>35 \mathrm{~mm}$ ) can make valve preservation challenging (especially in the presence of severe AI). Reduction of aortic annulus diameter through an annuloplasty or using a reimplantation technique is an effective way of reducing annular diameter, but can be more difficult in a very large annulus such as is sometimes observed in young adults with heritable aortic disorders (HAD) or unicuspid aortic valves (13). STJ dilatation can always be corrected but it is important to understand that the larger the original STJ diameter, the more extensive the reduction in intercommissural distance is when performing a VSRR. This is inevitably associated with a certain degree of induced cusp prolapse which should be assessed and corrected to ensure good durability of the repair (14).

If an eccentric jet of $\mathrm{AI}$ is present, suitability and durability 
of the VSRR procedure should be carefully assessed. In the presence of cusp calcification, cusp retraction or major fenestrations, long-terms results after VSRR are less favorable (15-17). In this context, individualized decisions should be made while taking other elements into consideration such as patient age, lifestyle, desire for future pregnancy, etc. Considerable understanding of the impact of primary cusp anomalies on long-term outcomes has been accrued in recent years. Similarly, the role of different cusp repair techniques is also better appreciated. Whereas correction of cusp prolapse using central plication sutures is a durable and reliable technique, subcommissural annuloplasty to improve cusp coaptation or use of pericardial patch material have both been associated with suboptimal results $(18,19)$.

\section{Patient characteristics}

In addition to aortic root anatomy, individual patient characteristics should be considered, namely patient age and comorbidities. It is now well established that prosthetic aortic valve replacement in non-elderly adults is associated with excess long-term mortality versus the general population $(20,21)$. Therefore, the younger the patient at the time of surgery, the more efforts should be made to perform a VSRR procedure. Of course, this should be weighed against the risk of reintervention for recurrent AI. At the other end of the spectrum, in elderly patients, although the benefits of performing a VSRR may be more marginal, there is little reason to systematically replace a functional aortic valve unless surgical expertise is limited or the patient requires a number of concomitant procedures such as mitral valve intervention or coronary revascularization. It is important to know that in older patients ( $>65-70$ years of age), aortic root aneurysms are seldom associated with aortic annular dilatation. In these patients, a simple remodeling procedure is often enough to address the root disease and ensure adequate valve function, which makes it a shorter operation than a reimplantation procedure or remodeling with extra-aortic annuloplasty.

Because VSRR requires longer cross-clamp and cardiopulmonary bypass times than CVGs, it is important to factor patient comorbidities into the choice of surgical procedure. In the presence of significant left ventricular dysfunction, diffuse coronary disease, chronic renal dysfunction or other systemic conditions that may independently impact the patient's mid- to long-term vital prognosis, it may be more judicious to proceed with a CVG in order to minimize immediate operative risk.
Finally, in patients with connective tissue disorders, significant chest deformities (especially pectus excavatum) can hinder access to the aortic root and render a VSRR procedure more difficult, especially in the presence of significant AI. In those instances, unless a perfect result can be obtained, it could be wiser to perform a CVG replacement, considering the added difficulty of an eventual redo intervention following VSRR.

\section{Bicuspid valves}

While the techniques of VSRR were originally designed to address root aneurysms in patients with tricuspid aortic valves, they can be adapted to suit patients with bicuspid morphology. Important considerations in this subset of patients are commissural height and orientation, cusp geometric height, aortic annulus dilatation and the presence of cusp prolapse $(22,23)$. Careful valve assessment and patient selection is crucial in order to achieve mid- to longterm durability of the operation (24). When a raphe is present, raphe mobilization allows improved cusp mobility by increasing the geometric height of the fused cusp. Central plication sutures on the free edge of the fused cusp is an effective means of correcting cusp prolapse. However, this inevitably reduces leaflet excursion, which is mitigated by placing the commissures closer to a 180-180 degrees orientation within the neo-root, all the while ensuring that the non-fused cusp remains freely mobile. Any restriction of cusp mobility results in higher postoperative gradients and will lead to cusp calcification in the mid- to longterm. Extensive repair, especially with the use of pericardial patches has been associated with higher rates of valve failure and reintervention $(19,25)$, and in those cases a CVG or Ross procedure may be a preferable approach. To date, there are only limited cohort studies of bicuspid valvesparing procedures with mean follow-ups $>10$ years. It is therefore difficult to state firm data on long-term outcomes. Nevertheless, the principles of bicuspid aortic valve repair are now clearly understood and standardized (24), and there is little doubt about the feasibility and mid-term durability of the operation (26-28). Indeed, in high volume centers with appropriate surgical expertise, results in bicuspid patients are comparable to those of patients with tricuspid valves (26-29).

\section{Aortic dissection}

In patients with acute type A aortic dissections, VSRR can be performed safely in experienced centers $(30,31)$, 


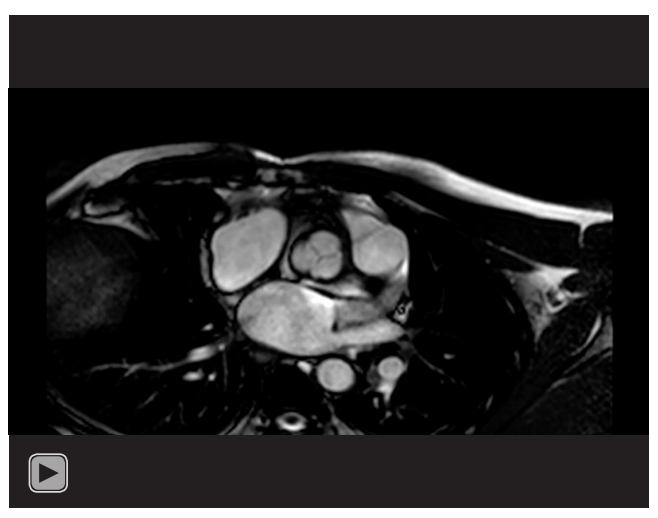

Video 1 Root motion in a normal aortic root.

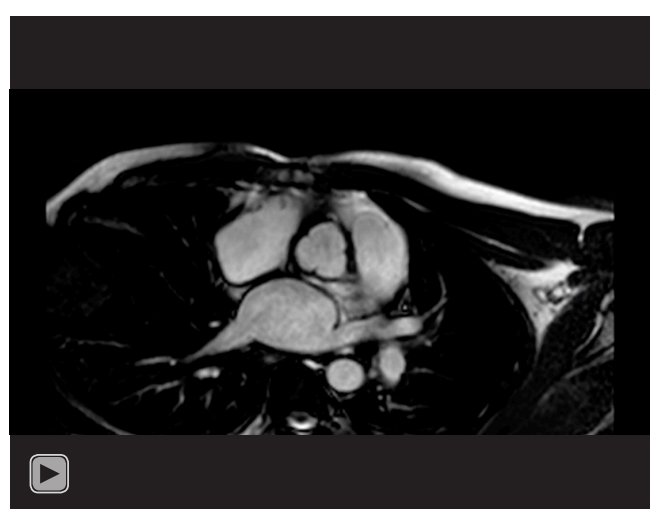

Video 2 Root motion after a remodeling with extra-aortic ring annuloplasty.

including in patients requiring extensive arch surgery and in patients presenting with malperfusion (32-34). A recent meta-analysis comparing composite grafts and VSRR has shown that the latter is associated with excellent early and long-term survival (35). However, VSRR is obviously a longer operation than a CVG and this needs to be considered, especially in older patients, or those with hemodynamic instability or end-organ malperfusion. In this context, short-term outcomes supersede the long-term benefits of the intervention.

Close postoperative follow-up is mandated in patients undergoing VSRR in the context of acute aortic dissection. A number of studies have found higher rates of reintervention when compared with the Bentall procedure $(32,33,35)$. Since AR appears to be the most common cause of reintervention, careful valve analysis, correction of cusp prolapse, and annulus stabilisation appear essential to ensure good long-term outcomes. Because it stabilizes the annulus and especially because it provides more predictable hemostasis, reimplantation represents a reliable method of VSRR in the context of acute aortic dissection, although some groups have also reported excellent outcomes with the remodeling procedure (36).

\section{Surgical technique}

For a long time, the main discussion about VSRR technique was around the question of remodeling versus reimplantation. Overall, long-term results following both procedures are excellent $(27,37,38)$. Nevertheless, early results suggested higher rates of reintervention in patients who underwent a remodeling procedure $(6,39,40)$. This has led to a better understanding of the factors associated with long-term durability of VSRR procedures, including the importance of annular stabilization at the time of surgery. Though the remodeling procedure acts as an annular reduction by pulling the commissures upward and correcting the splayed sub-commissural triangles, in a subset of patients this may prove insufficient in the long-term, leading to recurrent AI. As a result, several techniques of extra-aortic annuloplasty have been suggested to mitigate this issue (41-43) and preserve near-normal root distensibility (Videos 1,2). On the other hand, studies have found that the reimplantation using a straight Dacron graft fails to reproduce the normal hemodynamics usually found in the sinuses of Valsalva, leading to concerns about accelerated leaflet deterioration (44). These observations have led to the development of various approaches to recreate neo-sinuses with the reimplantation procedure (45).

Today, the issue of remodeling versus reimplantation belongs more to the past. Importantly, the principles of surgical repair associated with VSRR using either technique are clearly defined: stabilization of the aortic annulus (basal ring), creation of neo-sinuses of Valsalva, reduction and stabilization of the STJ and restoration of cusp geometry within the new aortic root $(46,47)$. All these basic principles can be achieved with equal effectiveness using either a reimplantation procedure or a remodeling procedure with aortic annuloplasty $(11,27,37,41)$. One of the critical elements to obtaining good results however is the issue of surgeon and center expertise. Indeed, as in any complex procedures, outcomes are intimately correlated with surgical volumes. It is therefore extremely important to work towards establishing reference centers for reconstructive aortic root surgery. An example of our preferred approach, the remodeling with extra-aortic annuloplasty, is provided in Video 3. 


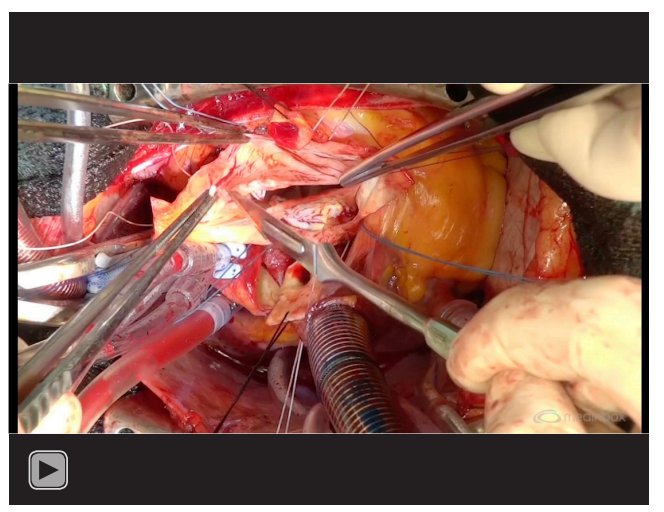

Video 3 Aortic root remodeling with extra-aortic annuloplasty.

\section{$H A D$}

Patients with HAD present a specific patient population in whom surgical technique is all the more important. They usually present for surgery at a young age and are therefore likely to benefit the most from a VSRR procedure in the long-term. Growing knowledge about the various forms of syndromic and familial forms of aortopathies dictates a thorough examination and exploration of family history, considering more malignant natural history which might trigger earlier surgical intervention. Importantly, in all these patients, special attention should be aimed at stabilizing the aortic annulus (basal ring). Indeed, long-term studies in patients with Marfan syndrome undergoing VSRR demonstrated higher risk of reintervention associated with the original remodeling technique when compared with the reimplantation procedure $(6,48)$. This was mostly attributable to continued dilatation of the aortic annulus. In light of this finding, it appears imperative to stabilize the annulus in these patients, whether through a reimplantation procedure or an aortic annuloplasty (using a ring or suture) $(38,49,50)$, although the stability of the latter approach remains to be determined in the long-term. Nevertheless, a recent multicentric study from centers of expertise examining outcomes of the reimplantation procedure in patients with Marfan syndrome reports a cumulative incidence of recurrent $\mathrm{AI}$ of $\sim 7 \%$ at only 1 year after surgery (51), highlighting the importance of careful patient selection and surgical technique.

\section{Conclusions}

Valve sparing root replacement (VSRR) procedures, using a reimplantation or remodeling with annuloplasty technique, represent safe and reproducible procedures. Improved understanding of long-term determinants of patient outcomes following these operations has led to refinements in surgical techniques as well as better determination of favorable patient characteristics. Continued follow-up of these patients, including multicentric registry data, will result in further advances in the field of reconstructive aortic root surgery.

\section{Acknowledgments}

Funding: None.

\section{Footnote}

Provenance and Peer Review: This article was commissioned by the Guest Editors (Filip Casselman and Johan van der Merwe) for the series "Aortic and Mitral Valve Innovative Surgery" published in Fournal of Visualized Surgery. The article has undergone external peer review.

Conflicts of Interest: All authors have completed the ICMJE uniform disclosure form (available at https://jovs.amegroups. com/article/view/10.21037/jovs.2020.02.05/coif). The series "Aortic and Mitral Valve Innovative Surgery" was commissioned by the editorial office without any funding or sponsorship. The authors have no other conflicts of interest to declare.

Ethical Statement: The authors are accountable for all aspects of the work in ensuring that questions related to the accuracy or integrity of any part of the work are appropriately investigated and resolved. All procedures performed in this study were in accordance with the Helsinki Declaration (as revised in 2013). The manuscript is waived from patient informed consent according to the ethics committee or institutional review board.

Open Access Statement: This is an Open Access article distributed in accordance with the Creative Commons Attribution-NonCommercial-NoDerivs 4.0 International License (CC BY-NC-ND 4.0), which permits the noncommercial replication and distribution of the article with the strict proviso that no changes or edits are made and the original work is properly cited (including links to both the formal publication through the relevant DOI and the license). See: https://creativecommons.org/ licenses/by-nc-nd/4.0/. 


\section{References}

1. Johnston DR, Soltesz EG, Vakil N, et al. Long-Term Durability of Bioprosthetic Aortic Valves: Implications From 12,569 Implants. Ann Thorac Surg 2015;99:1239-47.

2. Forcillo J, El Hamamsy I, Stevens LM, et al. The Perimount Valve in the Aortic Position: Twenty-Year Experience With Patients Under 60 Years Old. Ann Thorac Surg 2014;97:1526-32.

3. Sarsam MA, Yacoub M. Remodeling of the aortic valve anulus. J Thorac Cardiovasc Surg 1993;105:435-8.

4. David TE, Feindel CM. An aortic valve-sparing operation for patients with aortic incompetence and aneurysm of the ascending aorta. J Thorac Cardiovasc Surg 1992;103:61721; discussion 22.

5. Price J, Magruder JT, Young A, et al. Long-term outcomes of aortic root operations for Marfan syndrome: A comparison of Bentall versus aortic valve-sparing procedures. J Thorac Cardiovasc Surg 2016;151:330-6.

6. David TE, Feindel CM, Webb GD, et al. Long-term results of aortic valve-sparing operations for aortic root aneurysm. J Thorac Cardiovasc Surg 2006;132:347-54.

7. Birks EJ, Webb C, Child A, et al. Early and LongTerm Results of a Valve-Sparing Operation for Marfan Syndrome. Circulation 1999;100:II29-35.

8. Ouzounian M, Rao V, Manlhiot C, et al. Valve-Sparing Root Replacement Compared With Composite Valve Graft Procedures in Patients With Aortic Root Dilation. J Am Coll Cardiol 2016;68:1838-47.

9. Lim JY, Kim JB, Jung SH, et al. Surgical Management of Aortic Root Dilatation with Advanced Aortic Regurgitation: Bentall Operation versus Valve-sparing Procedure. Korean J Thorac Cardiovasc Surg 2012;45:141-7.

10. Franke UFW, Isecke A, Nagib R, et al. Quality of Life After Aortic Root Surgery: Reimplantation Technique Versus Composite Replacement. Ann Thorac Surg 2010;90:1869-75.

11. David TE. Aortic Valve Sparing in Different Aortic Valve and Aortic Root Conditions. J Am Coll Cardiol 2016;68:654-64.

12. Stamou SC, Williams ML, Gunn TM, et al. Aortic root surgery in the United States: A report from the Society of Thoracic Surgeons database. J Thorac Cardiovasc Surg 2015;149:116-22.e4.

13. Noly PE, Basmadjian L, Bouhout I, et al. New Insights Into Unicuspid Aortic Valve Disease in Adults: Not Just a Subtype of Bicuspid Aortic Valves. Can J Cardiol 2016;32:110-6.
14. Pethig K, Milz A, Hagl C, et al. Aortic valve reimplantation in ascending aortic aneurysm: risk factors for early valve failure. Ann Thorac Surg 2002;73:29-33.

15. de Kerchove L, Boodhwani M, Glineur D, et al. Cusp Prolapse Repair in Trileaflet Aortic Valves: Free Margin Plication and Free Margin Resuspension Techniques. Ann Thorac Surg 2009;88:455-61.

16. Kunihara T, Aicher D, Rodionycheva S, et al. Preoperative aortic root geometry and postoperative cusp configuration primarily determine long-term outcome after valvepreserving aortic root repair. J Thorac Cardiovasc Surg 2012;143:1389-95.

17. Yanagawa B, Mazine A, El-Hamamsy I. Predictors of Aortic Valve Repair Failure. Innovations 2019;14:199-208.

18. Navarra E, El Khoury G, Glineur D, et al. Effect of annulus dimension and annuloplasty on bicuspid aortic valve repair†. Eur J Cardiothorac Surg 2013;44:316-22.

19. Karliova I, Schneider U, Ehrlich T, et al. Results of Pericardial Patches in Tricuspid and Bicuspid Aortic Cusp Repair. Ann Thorac Surg 2020;109:728-35.

20. Goldstone AB, Chiu P, Baiocchi M, et al. Mechanical or Biologic Prostheses for Aortic-Valve and Mitral-Valve Replacement. N Engl J Med 2017;377:1847-57.

21. Bourguignon T, Lhommet P, El Khoury R, et al. Very long-term outcomes of the Carpentier-Edwards Perimount aortic valve in patients aged $50-65$ years $\dagger$. Eur J Cardiothorac Surg 2016;49:1462-8.

22. Aicher D, Kunihara T, Abou Issa O, et al. Valve Configuration Determines Long-Term Results After Repair of the Bicuspid Aortic Valve. Circulation 2011;123:178-85.

23. de Kerchove L, Mastrobuoni S, Froede L, et al. Variability of repairable bicuspid aortic valve phenotypes: towards an anatomical and repair-oriented classification $\dagger$. Eur J Cardiothorac Surg 2019;56:351-9.

24. Ram D, Bouhout I, Karliova I, et al. Concepts of Bicuspid Aortic Valve Repair; A Review. Ann Thorac Surg 2020;109:999-1006.

25. Ram E, Moshkovitz Y, Shinfeld A, et al. Pericardial Patch Augmentation Is Associated With a Higher Risk of Recurrent Aortic Insufficiency. Ann Thorac Surg 2018;106:1171-7.

26. Bavaria JE, Desai N, Szeto WY, et al. Valve-sparing root reimplantation and leaflet repair in a bicuspid aortic valve: Comparison with the 3-cusp David procedure. J Thorac Cardiovasc Surg 2015;149:S22-8.

27. de Kerchove L, Boodhwani M, Glineur D, et al. Valve sparing-root replacement with the reimplantation 
technique to increase the durability of bicuspid aortic valve repair. J Thorac Cardiovasc Surg 2011;142:1430-8.

28. Ouzounian M, Feindel C, Manlhiot C, et al. Valve-Sparing Root Replacement in Patients with Bicuspid vs Tricuspid Aortic Valves. Can J Cardiol 2017;33:S108-S9.

29. Aicher D, Langer F, Kissinger A, et al. Valve-sparing aortic root replacement in bicuspid aortic valves: A reasonable option? J Thorac Cardiovasc Surg 2004;128:662-8.

30. Leyh RG, Fischer S, Kallenbach K, et al. High Failure Rate After Valve-sparing Aortic Root Replacement Using the "Remodeling Technique" in Acute Type A Aortic Dissection. Circulation 2002;106:I229-33.

31. Erasmi AW, Stierle U, Bechtel JFM, et al. Up to 7 years' experience with valve-sparing aortic root remodeling/ reimplantation for acute type a dissection. Ann Thorac Surg 2003;76:99-104.

32. Beckmann E, Martens A, Alhadi FA, et al. Is Bentall Procedure Still the Gold Standard for Acute Aortic Dissection with Aortic Root Involvement? Thorac cardiovasc Surg 2016;64:116-23.

33. Kallenbach K, Oelze T, Salcher R, et al. Evolving Strategies for Treatment of Acute Aortic Dissection Type A. Circulation 2004;110:II243-9.

34. Graeter TP, Langer F, Nikoloudakis N, et al. Valvepreserving operation in acute aortic dissection type A. Ann Thorac Surg 2000;70:1460-5.

35. Wu J, Huang Y, Qiu J, et al. Is valve-sparing root replacement a safe option in acute type A aortic dissection? A systematic review and meta-analysis. Interact Cardiovasc Thorac Surg 2019;29:766-75.

36. Kunihara T, Neumann N, Kriechbaum SD, et al. Aortic root remodeling leads to good valve stability in acute aortic dissection and preexistent root dilatation. J Thorac Cardiovasc Surg 2016;152:430-6.e1.

37. Lenoir M, Maesen B, Stevens L-M, et al. Reimplantation versus remodelling with ring annuloplasty: comparison of mid-term outcomes after valve-sparing aortic root replacement†. Eur J Cardiothorac Surg 2018;54:48-54.

38. Schneider U, Ehrlich T, Karliova I, et al. Valvesparing aortic root replacement in patients with Marfan syndrome-the Homburg experience. Ann Cardiothorac Surg 2017;6:697-703.

39. Bethea BT, Fitton TP, Alejo DE, et al. Results of aortic valve-sparing operations: Experience with remodeling and reimplantation procedures in 65 patients. Ann Thorac Surg 2004;78:767-72.
40. Liu L, Wang W, Wang X, et al. Reimplantation Versus Remodeling: A Meta-Analysis. J Card Surg 2011;26:82-7.

41. Lansac E, Di Centa I, Varnous S, et al. External Aortic Annuloplasty Ring for Valve-Sparing Procedures. Ann Thorac Surg 2005;79:356-8.

42. Schneider U, Hofmann C, Aicher D, et al. Suture Annuloplasty Significantly Improves the Durability of Bicuspid Aortic Valve Repair. Ann Thorac Surg 2017;103:504-10.

43. Youssefi P, El-Hamamsy I, Lansac E. Rationale for aortic annuloplasty to standardise aortic valve repair. Ann Cardiothorac Surg 2019;8:322-30.

44. Leyh RG, Schmidtke C, Sievers HH, et al. Opening and Closing Characteristics of the Aortic Valve After Different Types of Valve-Preserving Surgery. Circulation 1999;100:2153-60.

45. De Paulis R, Matteis GMD, Nardi P, et al. A new aortic Dacron conduit for surgical treatment of aortic root pathology. Ital Heart J 2000;1:457-63.

46. Youssefi P, Di Centa I, Khelil N, et al. Valve sparing root replacement: remodeling root repair with aortic ring annuloplasty. Ann Cardiothorac Surg 2019;8:411-4.

47. Aphram G, Tamer S, Mastrobuoni S, et al. Valve sparing root replacement: reimplantation of the aortic valve. Ann Cardiothorac Surg 2019;8:415-7.

48. Benedetto U, Melina G, Takkenberg JJM, et al. Surgical management of aortic root disease in Marfan syndrome: a systematic review and meta-analysis. Heart 2011;97:955-8.

49. David TE, David CM, Manlhiot C, et al. Outcomes of Aortic Valve-Sparing Operations in Marfan Syndrome. J Am Coll Cardiol 2015;66:1445-53.

50. Lansac E, Di Centa I, Sleilaty G, et al. An aortic ring: From physiologic reconstruction of the root to a standardized approach for aortic valve repair. J Thorac Cardiovasc Surg 2010;140:S28-35.

51. Coselli JS, Volguina IV, LeMaire SA, et al. Early and 1-year outcomes of aortic root surgery in patients with Marfan syndrome: A prospective, multicenter, comparative study. J Thorac Cardiovasc Surg 2014;147:1758-66, 67.e1-4.

doi: $10.21037 /$ jovs.2020.02.05

Cite this article as: Chauvette V, Chamberland MÈ, Lefebvre L, El-Hamamsy I. Aortic valve sparing surgery-patient selection and techniques. J Vis Surg 2021;7:7. 